\title{
Digital Design and Wooden Architecture for Arte Sella Land Art Park
}

\author{
Marco Imperadori, Marco Clozza, Andrea Vanossi and Federica Brunone
}

\begin{abstract}
Digital design is increasingly sinking the construction sector, shaping and validating architecture according to various criteria and introducing the wood industry to the 4.0 approach. Within the study entitled "Architecture at Arte Sella", parametric design, structural validations and CNC procedures are exploited to help define, control and assess several architectural woodworks, created with famous designers. This contribution describes the design and construction experiences of Atsushi Kitagawara (2017) and Kengo Kuma (2018-2019), the two masterpieces installed in the land art park of Arte Sella (Trento, Italy) and developed, thanks to the Politecnico di Milano team, from design to mock-ups, testing and construction.
\end{abstract}

Keywords Diffuse lattice structure - Parametric design · FEM-based structural analysis $\cdot$ CNC-based processes $\cdot$ Wooden land art

\section{Introduction}

Digital design is increasingly sinking the construction sector, shaping and validating architecture according to various criteria (Vanossi 2018; Tedeschi 2014; Vanossi and Imperadori 2013), and supporting the realizations at several stages and dimensions of the construction process (Eastman et al. 2008).

It has found, in particular, a ready stage for a 4.0 approach within the wood-based industry, thanks to computer-aided design (CAD) and computer-aided manufacturing (CAM) systems, already available for timber solutions, both within the design and

\footnotetext{
M. Imperadori $(\varangle) \cdot$ F. Brunone

Architecture, Built Environment and Construction Engineering-ABC Department,

Politecnico di Milano, Milan, Italy

e-mail: marco.imperadori@polimi.it
}

M. Clozza

D3WOOD, Lecco, Italy
A. Vanossi
CMB, Carpi, Italy
(C) The Author(s) 2020
B. Daniotti et al. (eds.), Digital Transformation of the Design, Construction and Management Processes of the Built Environment, Research for Development, https://doi.org/10.1007/978-3-030-33570-0_15 
architecture fields (Bianconi and Filippucci 2019b). Numerous experiences (Bianconi and Filippucci, 2019a; Imperadori et al. 2019; Kobayashi and O'Keefe 2019; Imperadori and Brunone 2018; Kuma 2018; Kobayashi 2017; Kuma and Daniell 2015; Menges et al. 2016; Vanossi et al. 2014, 2015), indeed, have demonstrated the wide spectrum of possible applications for digitalized processes to wooden realizations - artworks, land/urban art pieces, small-scale pavilions and so on-from computational design to digital fabrication, robotics and so on.

Within this field, the research project "Architecture at Arte Sella" has defined the opportunity to develop a continuous and iterative workflow, based on parametric design, structural validations and computer numerical control $(\mathrm{CNC})$ procedures to define, control and assess several wooden installations, all characterized by an inner complexity of conception, production, assembly and structural validation. After a detailed description of the followed process methodology, this paper refers to, specifically, two design and construction experiences of masterpieces, first conceived for Arte Sella (Montibeller et al. 2017; http://www.artesella.it/en/), a mountain land art park near Trento, Italy. The first one is the Forest Byobu (2017) conceived in collaboration with Atsushi Kitagawara and AKA as a re-use project for the outstanding wooden structural lattice of the Japan Pavilion façade at EXPO Milano 2015 (Figs. 1, 2 and 3) (Kitagawara et al. 2019). The second one is Kodama, a wooden blades lattice defining a small polyhedral pavilion (Figs. 4, 5 and 6), by Kengo Kuma (Kuma et al. 2019). Both wooden structures have been developed, thanks to the team of Politecnico di Milano, collaborating with the most innovative and advanced research teams and industries of the fields, from design to mock-ups, testing, construction and maintenance, and leading to a methodology which has since then been replicated in several later experiences, between Italy (Lecco, Favara, and Ischia), Japan (Tokyo) and Taiwan.

\section{Process Methodology}

Since its kick-off in 2017, "Architecture for Arte Sella" has counted already the realization of several wooden artworks for this inspiring land art park in the valley of Borgo Valsugana (Montibeller et al. 2017; http://www.artesella.it/en/).

Reading into a cross-section of all these experiences let us trace a defined, shared and, therefore, validated method of design, assessment and realization, which has been applied to each project, applying CAD, CAM and BIM at different levels of development for the different stages of the process. Indeed, the methodology accounts for computational design of timber elements, joinery and three-dimensional structures from the very beginning of the design conception to structural validation, right up to digital fabrication through $\mathrm{CNC}$-cutting processes, along with the management of construction issues, but always looking to the materiality of architecture as well and the need to assess all the stages in a hands-on fashion, via mock-ups and tests. The process thus far defined can be outlined as follows, considering each stage as 

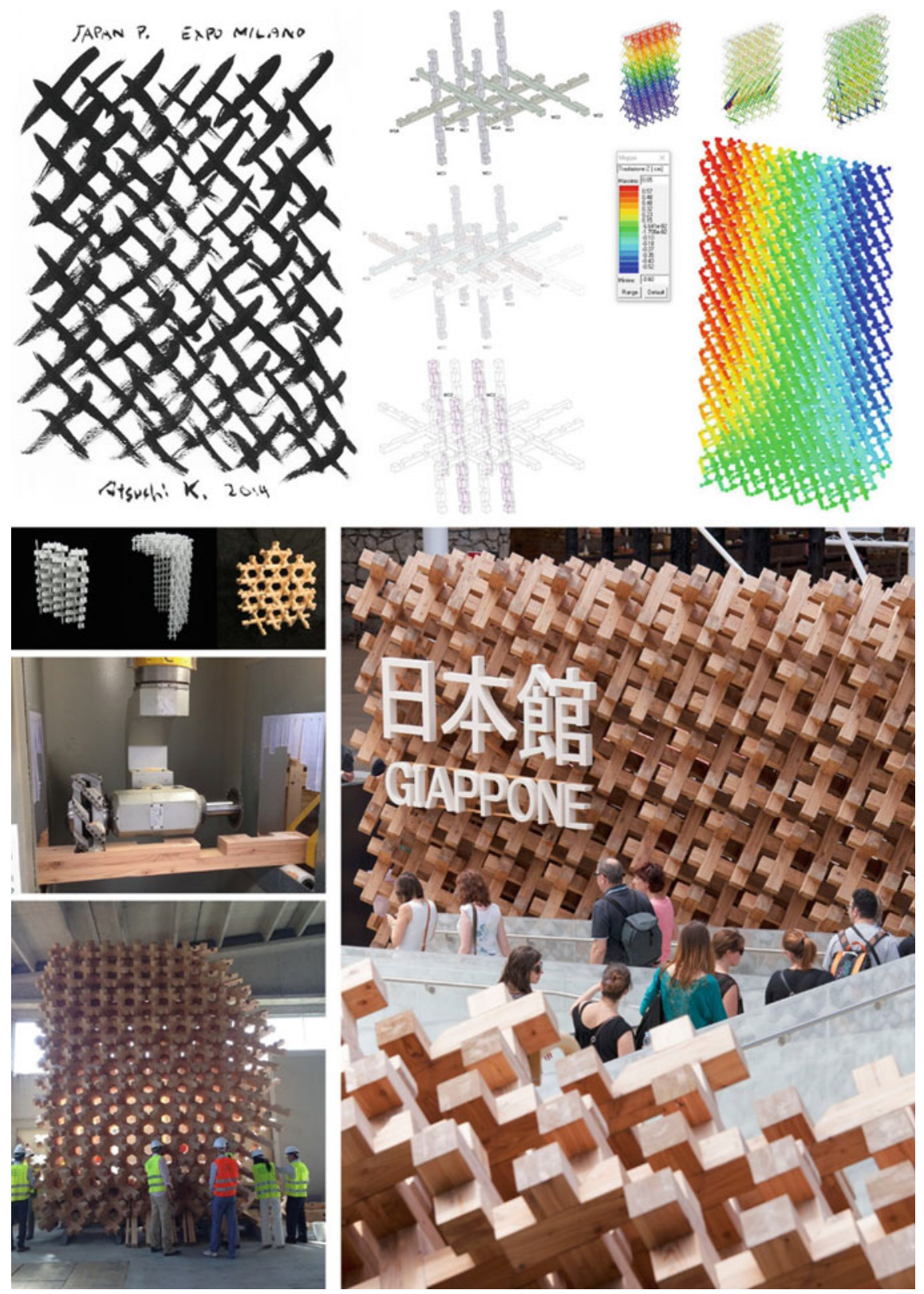

Fig. 1 Japan Pavilion wooden façade, conceived and realized for EXPO Milano 2015, thanks to an intense and iterative process between computational and parametric design, FEM-based structural analysis and digital fabrication with $\mathrm{CNC}$ machines, which allow both real scale mock-ups and final fast and precise assembling on site (drawings and photo courtesy Atsushi Kitagawara Architects and Galloppini Legnami) 

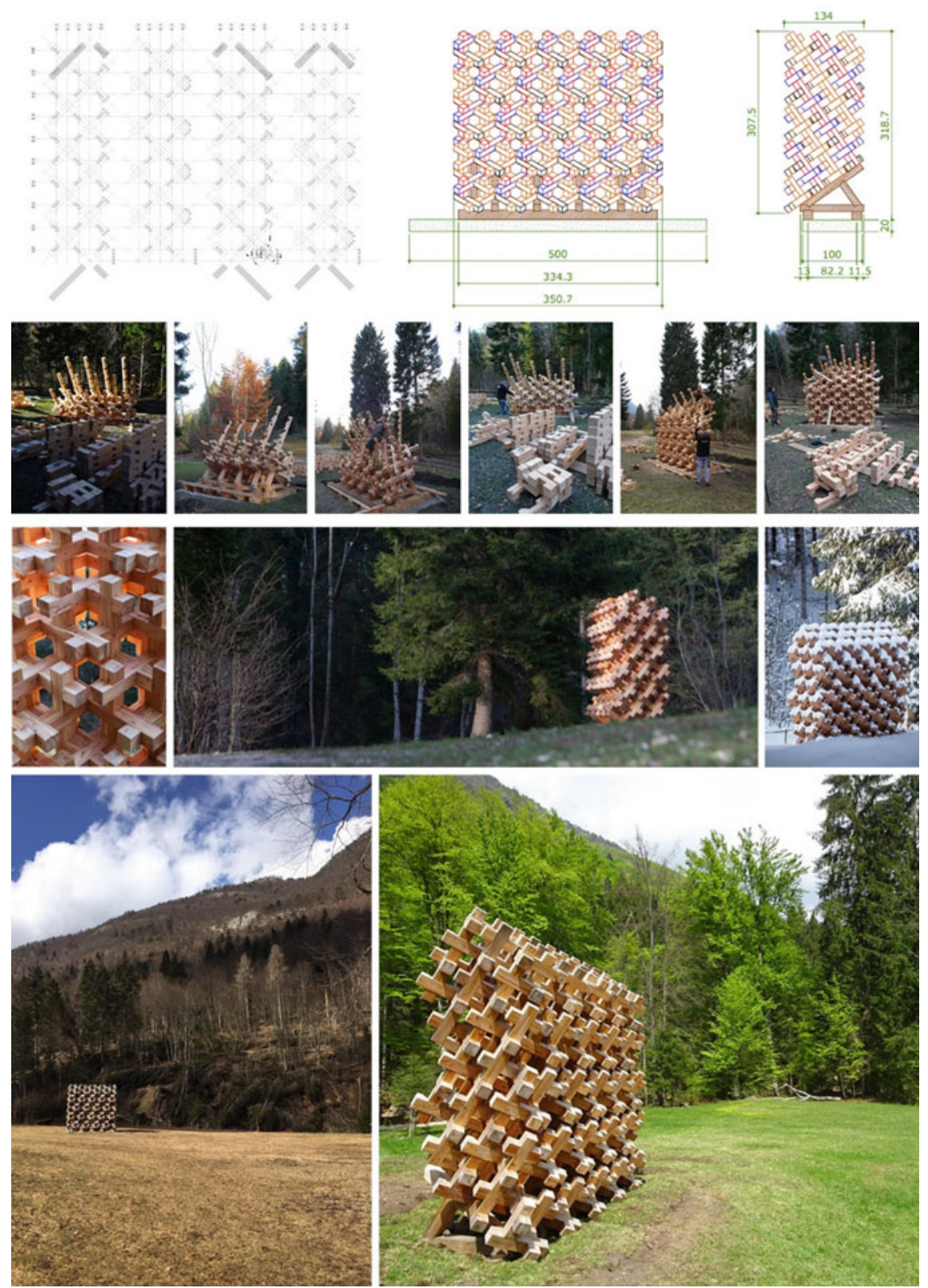

Fig. 2 Forest Byobu design definition (drawings credit Galloppini Legnami and Politecnico di Milano) and assembling phases (credit Politecnico di Milano), up to the final complete structure, a geometric pattern contrasting the natural landscape of its location at Arte Sella, the Contemporary Mountain (credits for the first row, Ph. Giacomo Bianchi for Arte Sella; for the latter, Politecnico di Milano) 

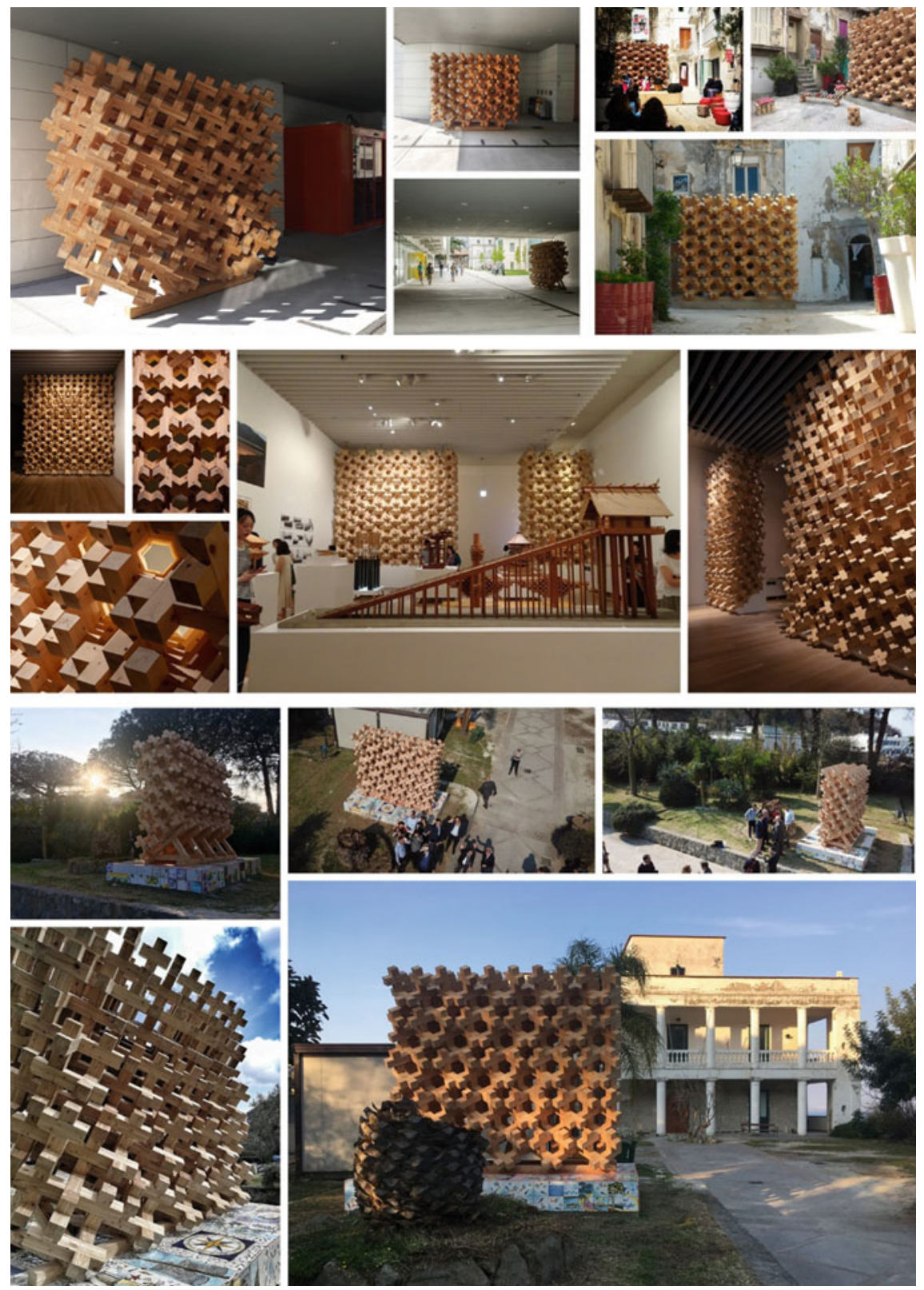

Fig. 3 The Byobu experiences. Above to the left, the University Byobu in Politecnico di MilanoLecco campus (source Politecnico di Milano) and, to the right, the Urban Byobu at FARM Cultural Park, Favara (source Politecnico di Milano); in the middle, the Kigumi Infinity Byobu at Mori Museum of Tokyo (credit Ph. Shigeo Ogawa for Atsushi Kitagawara Architects); and finally the one on the island of Ischia (source Politecnico di Milano and PIDA Association) 

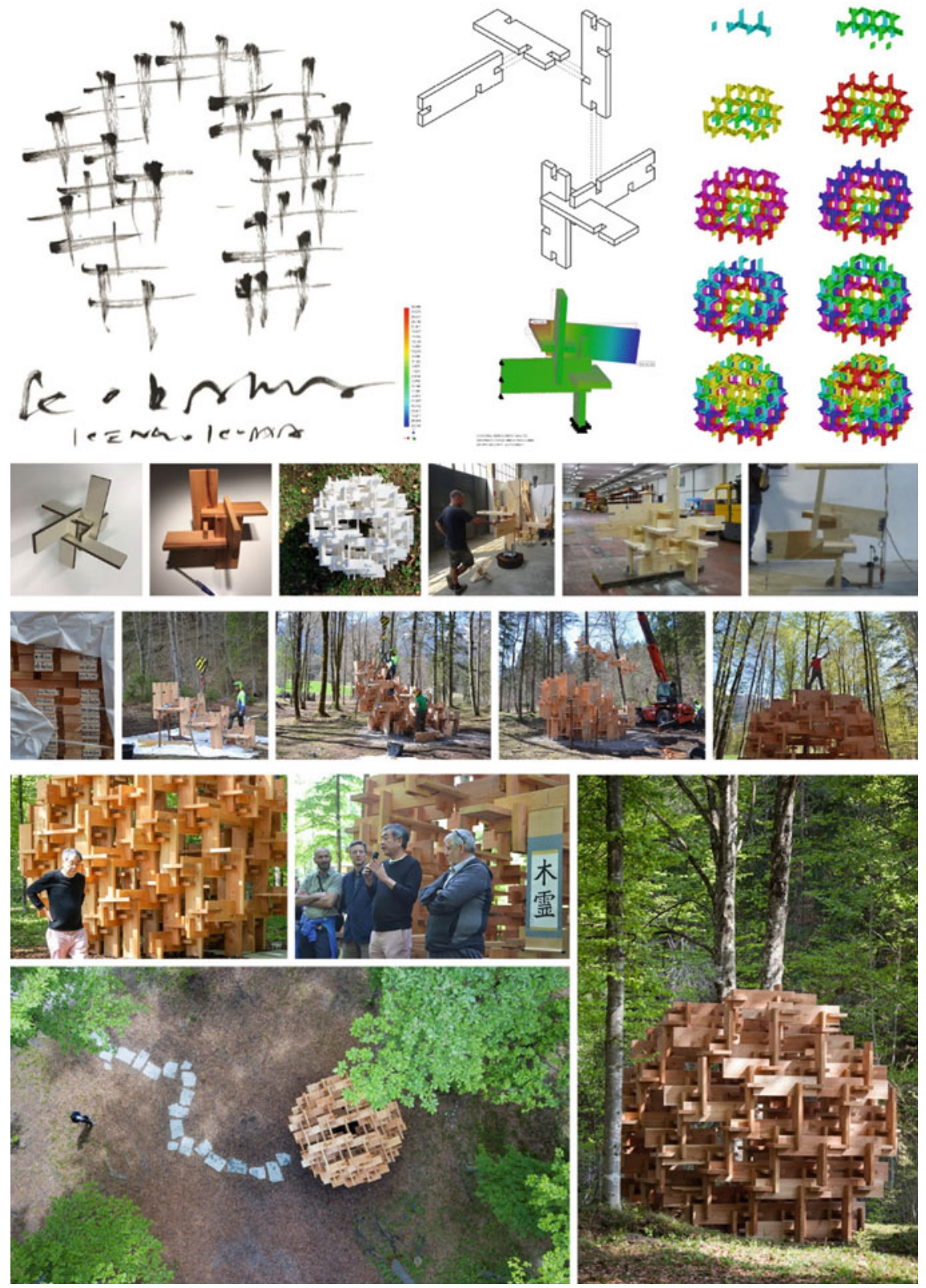

Fig. 4 Kodama Pavilion in Arte Sella, from the first sketch by Kengo Kuma, to the FEM-based structural validation and parametric management of elements' dimensions, codifications and assembling phases; in the middle, the infinite number of mock-ups realized through digital fabrication and the assembling stages, performed by D3WOOD (credit Politecnico di Milano); lastly, Kengo Kuma land art masterpiece (credit $\mathrm{Ph}$. Giacomo Bianchi for Arte Sella) 

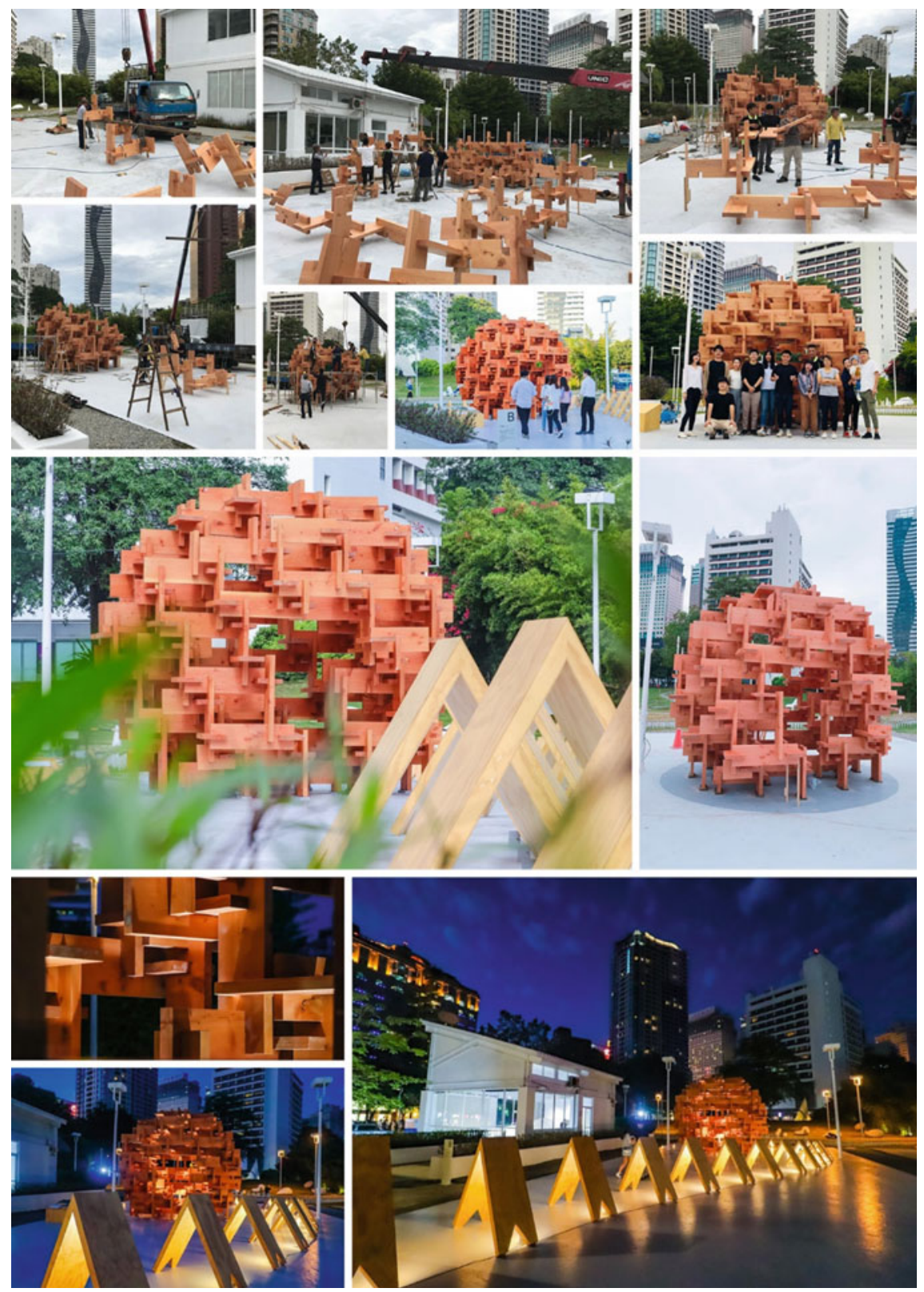

Fig. 5 The Taiwanese sample of Kodama Pavilion realized, accounting for the same digitalized processes of design and production, by Kengo Kuma Lab in 2018 (credit Ph. Takahiro Hirayama for Kengo Kuma Lab) 

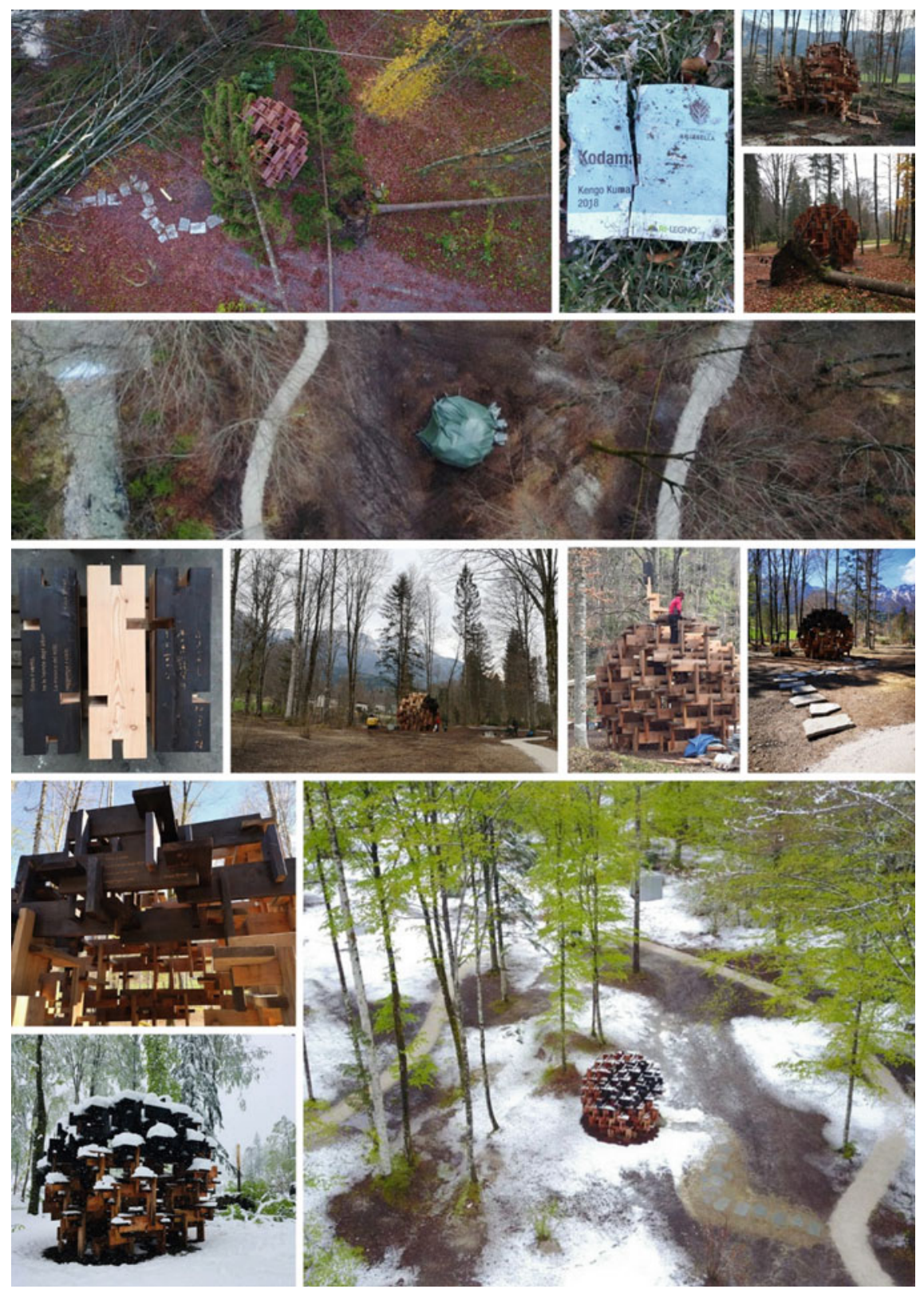

Fig. 6 Kodama 2.0 is the Arte Sella pavilion refurbishment damaged during the devastating storm of October 2018: the structure has been (i) protected to retain the humidity content of wood elements before restoration; (ii) new pieces have been cut via $\mathrm{CNC}$ machine, (iii) burned and carved to render a Japanese haiku on the surface, and (iv) relocated to its original location, obtaining a new aesthetic for the wooden lattice (credit Politecnico di Milano and Arte Sella) 
interconnected within an iterative workflow of conceptual hypothesis, parametric translation, virtual and/or real evaluation and validation:

- Design conception-beginning with the first sketches, the design concept passes through a parametric translation in order to optimize the singular elements of the construction as a module defined by parameters (e.g. dimension, mutual relation, and global proportion); the same is evaluated through real mock-ups at different scales, which are able to outline the real consistency of architecture, and can be elusive in virtual reality: space, as a relationship between solids and voids;

- Structural validation-finite elements methods (FEM)-based assessment procedures are carried out alongside structural tests on real prototypes, which are useful to assess the reliability of the virtual analysis of singular elements and joineries;

- Details and connections - the prototyping process, feasible exactly because of the CAM and CNC-based fabrication, allows for tests on a 1:1 scale of the construction details, such as wood-by-wood joinery and/or steel anchors to the ground, in terms of both structural stresses distribution and construction feasibility of the assembling processes (from the modular element to the whole timber structure);

- Production and assembly — at this final stage, BIM and parametric environments allow users to manage the CNC-based production, thanks to an open flux of data and information between the design and production files, where all the single pieces are unequivocally codified (minimizing the waste of resources); moreover, these methodologies help to set virtual assembling scenarios for the whole structure, in order to optimize construction (minimizing its timeframe).

This fil-rouge of digital design and fabrication has run throughout the experiences of Arte Sella, and indeed beyond them, since the same ones have been already replicated in several contests, attesting the reliability of this process methodology.

\section{Case Studies}

The outlined process has been applied on two different experiences (Byobu and Kodama pavilions), both started with the realization of the first samples (Forest Byobu and Kodama) located in Arte Sella and then continued with derivative projects (Urban Byobu, University Byobu, Kigumi Infinity Museum Byobu, and Kigumi Infinity Ischia Byobu; Kodama pavilion in Taiwan and Kodama 2.0, restoration project of the first original pavilion, after damages caused by a heavy storm), accounting for the methodology described above.

\subsection{Wooden Byobu: Atsushi Kitagawara}

Forest Byobu, and more generally the Byobu experiences all around Italy (and Japan), derives as a sequel from the EXPO Milano 2015 challenge to design and realize 
the wooden structure of the Japan Pavilion façade, tackled by Atsushi Kitaga wara Architects (www.kitagawara.co.jp), Ishimoto Architectural and Engineering Firm, and Ove Arup and Partners - for the design stage — and Galloppini Legnami-for the construction-with the collaboration of Politecnico di Milano. The project, indeed, had the initial aim to be preserved, thanks to the potential dismantling of the original façade lattice, a $115 \times 115 \mathrm{~mm}$ glulam studs' pattern created by the multiple woodby-wood connections of a modular element and resulting in a three-dimensional diffusive grid of solid joints and voids (with no metal connectors), as the Japanese aesthetic teaches. Here, parametric models helped in defining structure porosity, optimizing the studs' dimensions and proportions with the joints' distribution at the design stage; then the virtual model was used in order to assess the structural properties and distribution of loads along the timber lattice; finally, the data regarding single geometries were sent to the CNC machine for the production, both for initial prototypes and for the final realization (Fig. 1).

However, despite the intense endeavor behind its definition, the original structure has been dismantled, but the project has survived in the form of both the aesthetic potentials of its mock-ups and the replicability of its digital design/fabrication/assembling process (Kitagawara et al. 2019).

Forest Byobu, therefore, has been realized as a trace of the former façade, a $3.50 \times 3.20 \times 1.34 \mathrm{~m}$ sample of larch wood of the geometrical and rational wooden structure that went back to the forest, in contrast to its proper and natural landscape. The project followed the same design process; subsequently, all the larch timber elements were produced via CNC-based cutting processes, transferred to Arte Sella and assembled by Galloppini Legnami in just one day of operations (Fig. 2).

With the same dimensions and proportions, following an ideal connection of all the experiences, other samples of the so-defined Byobu have been realized, between Italy and Japan, once again thanks to the high replicability of the digital process behind the wooden structure. The last one has been the Kigumi Infinity Ischia Byobu, conceived for the seismic area of the island, left damaged since 2017 by a strong earthquake and still uninhabited. Here, the connections between the modular elements, repeated across the structure, and its following capability to resist as a whole to horizontal forces, being also self-bearing, aim to represent the possibility to find strength and resilience within the collaboration of singularities (Fig. 3).

\subsection{Kodama: Kengo Kuma}

Kodama pavilion at Arte Sella is a complex lattice structure of 335 massive larch blades realized out of the same dimensional proportions - $58 \mathrm{~mm}$ thick, $300 \mathrm{~mm}$ wide and $1000 \mathrm{~mm}$ long - the repetition and mutual connection with no steel elements of which result in a polyhedral volume of solids and voids, according to Kuma's theory of particles and diffused structures (Kuma and Daniell 2015).

Behind this mutual relation of complexity and simplicity, there has been an intense endeavor (Fig. 4), which relied on, at first, virtual parametric models to vary the 
blades' proportions, check the final geometry and help in the FEM-based structural verifications; after that, the model facilitated the production of the wooden elements via CNC-cutting processes, for the real prototyping assessment, by Ri-Legno and D3WOOD. The latter has been essential in order to test and validate the nodes' structural behavior and the construction feasibility in joineries of assembling six panels. In the end, the so-validated geometry - as a whole and a sum of connections of modular elements-was processed into digital environments in order to manage the pieces' production, codification and final assembly at Arte Sella (Kuma et al. 2019).

The digitalization of all the stages, from the first design conception to production and construction, was made possible not only to communicate and transfer data and ideas but more generally to adapt the process to other experiences, such as the one in Taiwan. This version of the Kodama, indeed, followed the same path of conception/production/assembling, in direct contact with D3WOOD and the Politecnico di Milano team, as a result of a workshop led by Kengo Kuma Lab and its students of Tokyo University (Fig. 5).

Finally, this open access process has been adapted once again.

In October 2018, a strong storm devastated the lands of Arte Sella park, killing millions of trees and destroying lots of beautiful masterpieces. The original Kodama Pavilion was heavily damaged. The restoration challenge was accepted (and won) by the team of Politecnico di Milano, Arte Sella, D3WOOD and Ri-Legno. Inspired by the ancient Japanese kintsugi crafting technique, which embraces the damages as a natural process of life and exalts them as golden scars, the destroyed blades have been removed and replaced with new ones, and that results in a vibrant variation of colors among the already existing preserved pieces and the new ones (produced via CNC-cutting procedures by Ri-Legno). The latter, indeed, has been treated by D3WOOD with the yakisugi technique, burnt in order to resist decay and be visible as a new intervention. Two of them have been, finally, carved with the words of Kaya Shirao's haiku Wind hisses through the treetops the music of Koto reaches the sky (in both Italian and Japanese), which fix the event on the structure as a "golden scar" carved by Nature itself (Fig. 3).

In this last case, the process has been facilitated by the digitalized method in recognizing the new elements needed, their production via digital fabrication and manufacturing, and allocation on site for the Kodama 2.0 experience.

\section{Conclusions and Further Developments of the Research Project}

The digitalization of the process, from design to assessment, production and construction, aims to gain better control over each phase and procedure, transferring the earlier ideas and sketches into an engineered knowledge. It is demonstrated by 
the real wooden structural prototypes, which have been able to go beyond numerical experimentations and become proper sculptures for the Arte Sella land art park, integrating creativity and engineering into art.

The new horizons of this research project include a new masterpiece by Ian Ritchie: Levitas. The grid-shell structure, conceived to float among the trees of Arte Sella mountain landscape, pushes the engineering challenge even further, introducing the field of reverse engineering, in order to control the complex geometries that the designer wants.

Acknowledgements The authors would like to credit and thank first the architects and designers who defined these three outstanding land art pieces for Arte Sella: Atsushi Kitagawara, Kengo Kuma and Ian Ritchie. A special acknowledgment goes also to Emanuele Montibeller Giacomo Bianchi and Floriano Tomio from Arte Sella-The Contemporary Mountain, for having joined with passion and enthusiasm every design challenge brought up by these experiences.

Finally, the authors would like to credit the design teams of designers, producers, researchers and students of Politecnico di Milano and thank them for their essential contribution to each realization. For the Byobu experiences: Kuwabara-san and Mayuko-san from AKA-Atsushi Kitagawara Architects, Atelier2-Arch. Valentina Gallotti, for the close collaboration, Galloppini Legnami, for the cooperation in developing details and the availability to make the structure reliable for re-use projects all-over Italy, PIDA association and arch. Giovannangelo De Angelis for the enthusiasm in realizing the last prototype as a symbolic art piece for their island, Gianluca Crippa, Chiara Re Depaolini, Roberta Simone and Mirko Borzone from the Politecnico di Milano. And for KODAMA and KODAMA 2.0, Toshiki Hirano, Prof. Jun Sato of the University of Tokyo and the Kengo Kuma lab team, the computational team of the Politecnico di Milano (Matteo Pedrana, Leandro Robutti and Fabrizio Miele), D3WOOD team (Marco and Claudio Clozza) and Ri-Legno Srl (Giulio Franceschini, Lavinia Sartori and Giorgio Franceschini) for the CNC work, Rothoblaas Srl and Elena Bonaldo from SFS for the material supply, Federica Iachelini and Clara Rinaldi of the Politecnico di Milano and Takahiro Hirayama, Masumi Ogawa and Ifan Yim, from the University of Tokyo.

\section{References}

Bianconi F, Filippucci M (eds) (2019a) Digital wood design. Lecture notes in civil engineering, vol 24. Springer, Cham

Bianconi F, Filippucci M (2019b) WOOD, CAD AND AI: digital modelling as place of convergence of natural and artificial intelligent to design timber architecture. In: Bianconi F, Filippucci M (eds) Digital wood design. Lecture notes in civil engineering, vol 24. Springer, Cham

Eastman C, Teicholz P, Sacks R, Liston K (2008) BIM handbook. A guide to building information modeling for owners, managers, designers, engineers, and contractors. Wiley \& Sons, Inc., Hoboken, New Jersey

Imperadori M, Salvalai G, Vanossi A, Brunone F (2019) SMALL IS MORE. Wooden Pavilion as a path of research. In: Bianconi F, Filippucci M (eds) Digital wood design. Lecture notes in civil engineering, vol 24. Springer, Cham

Imperadori M, Brunone F (2018) Insegnare costruendo. Architettura temporanea tra ricerca e didattica. AGATHÒN 04 Int J Archit Art Des 21-28

Kitagawara A, Imperadori M, Kuwabara R, Brunone F, Matsukawa M (2019) Wooden Byobu. From architectural façade to sculpture. In: Bianconi F, Filippucci M (eds) Digital wood design. Lecture notes in civil engineering, vol 24. Springer, Cham 
Kobayashi H, O'Keefe D (2019) Empathic architecture: digital fabrication and community participation. In: Bianconi F, Filippucci M (eds) Digital wood design. Lecture notes in civil engineering, vol 24. Springer, Cham

Kobayashi H (2017) The Veneer house experience: the role of architects in recovering community after disaster. In: Yan W, Galloway W (eds) Rethinking resilience, adaptation and transformation in a time of change. Springer, Cham

Kuma K, Imperadori M, Clozza M, Hirano T, Vanossi A, Brunone F (2019) KODAMA: a polyhedron sculpture in the forest at Arte Sella. In: Bianconi F, Filippucci M(eds) Digital wood design. Lecture notes in civil engineering, vol 24. Springer, Cham

Kuma K (2018) Ja 109 Kengo Kuma: a lab for materials. Shinkenchiku-sha Co Ltd., Tokyo

Kuma K, Daniell T (2015) Small architecture/natural architecture. Architectural Association Publications, London

Menges A, Schwinn T, Krieg OD (2016) Advancing wood architecture: a computational approach. Routledge, United Kingdom

Montibeller E, Tomaselli L, Bianchi G (2017) Arte Sella. The contemporary mountain. The new beginning. Silvana Ed., Milano

Tedeschi A (2014) AAD algorithms-aided design. Parametric strategies using grasshopper, Edizioni Le Penseur, Brienza

Vanossi A. (2018) Interaction and intersection between digital modelling and design in architecture: different approaches in parametric design. In: handbook of research on form and morphogenesis in modern architectural contexts, pp 152-174. Information Science Reference, Milano, February 2018

Vanossi A, Parello G, Imperadori M, Bernardo C, Liotta SJA, Ito Y, Occhipinti F (2015) Architecture for archeology: identifying new modular and flexible types of shelter adaptable to the diverse needs of archaeological sites. In: XII Forum Internazionale Le Vie dei Mercanti-proceedings, pp 457-466. La scuola di Pitagora, Anversa-Capri, June 2015

Vanossi A, Parello G, Imperadori M, Bernardo C, Liotta SJA, Ito Y (2014) BIM for archaeology, Use of BIM process and parametric model in a temporary shelter adaptable to the diverse needs of archaeological sites. In: PPC 2014 conference proceedings, pp 191-200, Monza, Mantova (Italy), May 2014

Vanossi A, Imperadori M (2013) BIM and optioneering in dry technology small-scale building. In: ICT, automation and the industry of the built environment, pp 53-65. Maggioli, Milano, March 2013

Open Access This chapter is licensed under the terms of the Creative Commons Attribution 4.0 International License (http://creativecommons.org/licenses/by/4.0/), which permits use, sharing, adaptation, distribution and reproduction in any medium or format, as long as you give appropriate credit to the original author(s) and the source, provide a link to the Creative Commons license and indicate if changes were made.

The images or other third party material in this chapter are included in the chapter's Creative Commons license, unless indicated otherwise in a credit line to the material. If material is not included in the chapter's Creative Commons license and your intended use is not permitted by statutory regulation or exceeds the permitted use, you will need to obtain permission directly from the copyright holder.

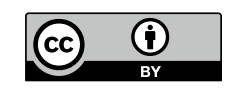

